\title{
Peroxiredoxin V Reduces $\beta$-Lapachone-induced Apoptosis of Colon Cancer Cells
}

\author{
YUE LIU $^{1 *}$, TAEHO KWON ${ }^{2 *}$, JI-SU KIM $^{2 *}$, NISANSALA CHANDIMALI ${ }^{3,4}$, \\ YING-HUA JIN ${ }^{1}$, YI-XI GONG ${ }^{1}$, DAN-PING XIE ${ }^{1}$, YING-HAO HAN ${ }^{1}$, MEI-HUA JIN ${ }^{1}$, GUI-NAN SHEN ${ }^{1}$, \\ DONG KEE JEONG ${ }^{4,5}$, DONG-SUN LEE ${ }^{5,6}$, YU-DONG CUI ${ }^{1}$ and HU-NAN SUN ${ }^{1,4,5}$ \\ ${ }^{I}$ College of Life Science \& Technology, Heilongjiang Bayi Agricultural University, Daqing, P.R. China; \\ ${ }^{2}$ Primate Resources Center, Korea Research Institute of Bioscience and \\ Biotechnology (KRIBB), Jeonbuk, Republic of Korea; \\ ${ }^{3}$ Immunotherapy Convergence Research Center, Korea Research Institute of Bioscience and \\ Biotechnology (KRIBB), Daejeon, Republic of Korea; \\ ${ }^{4}$ Laboratory of Animal Genetic Engineering and Stem Cell Biology, Advanced Convergence Technology \& Science, \\ Jeju National University, Jeju, Republic of Korea; \\ ${ }^{5}$ Subtropical/Tropical Organism Gene Bank, Jeju National University, Jeju, Republic of Korea; \\ ${ }^{6}$ Department of Biotechnology, College of Applied Life Science, Jeju National University, Jeju, Republic of Korea
}

\begin{abstract}
Background/Aim: Peroxiredoxin (Prx) V has been known as an antioxidant enzyme which scavenges intracellular reactive oxygen species (ROS). Also, Prx V has been shown to mediate cell apoptosis in various cancers. However, the mechanism of Prx V-induced apoptosis in colon cancer cells remains unknown. Thus, in this study we analyzed the effects of Prx V in $\beta$-lapachone-induced apoptosis in SW480 human colon cancer cells. Materials and Methods: $\beta$-lapachoneinduced apoptosis was analyzed by the MTT assay, western blotting, fluorescence microscopy, Annexin V staining and flow cytometry. Results: Overexpression of Prx V, significantly decreased $\beta$-lapachone-induced cellular apoptosis and $\operatorname{Prx} V$ silencing increased $\beta$-lapachone-induced cellular apoptosis via modulating ROS scavenging activity compared to mock SW480 cells. In addition, to further explore the mechanism of Prx $V$
\end{abstract}

*These Authors contributed equally to this work.

Correspondence to: Dong Sun Lee, Department of Biotechnology, College of Applied Life Science, Jeju National University, Jeju 63243 Republic of Korea. Tel: +82 647548275, Fax: +82 82647548275, email: dongsunlee@jejunu.ac.kr or Yu-Dong Cui, College of Life Science \& Technology, Heilongjiang Bayi Agricultural University, Xinyanglu, 163319, Daqing, P.R. China. Tel: +86 4596819300, Fax: +86 4596819295, e-mail: 1016856109@qq.com or Hu-Nan Sun, College of Life Science \& Technology, Heilongjiang Bayi Agricultural University, Xinyanglu, 163319, Daqing, P.R. China. Tel: +86 4596819300, Fax: +86 4596819295, e-mail: sunmkbb@qq.com

Key Words: Peroxiredoxin V, Apoptosis, $\beta$-lapachone, colon cancer, ROS. regulated $\beta$-lapachone-induced SW480 cells apoptosis, the $W n t / \beta$-catenin signaling was studied. The Wnt/ $\beta$-catenin signaling pathway was found to be induced by $\beta$-lapachone. Conclusion: Prx $V$ regulates $S W 480$ cell apoptosis via scavenging ROS cellular levels and mediating the Wnt/ $\beta$ catenin signaling pathway, which was induced by $\beta$-lapachone.

Colon cancer is the third most common cancer, and the fourth most common cause of cancer-related mortality worldwide $(1,2)$. According to the statistics of World Health Organization (WHO), 1.36 million new colon cancer cases and 0.69 million deaths have been reported worldwide in 2014.The survival rate of advanced colon cancer is very low. As American Cancer Society has reported, the 5-year survival rates of stage III and stage IV colon cancer are 53\% and $11 \%$, respectively (3). Therefore, a clear understanding of the underlying molecular mechanisms of colon cancer is necessary for the development of successful early diagnostic strategies and therapeutic management of colon cancer. Thus, we focused on the mechanism of action of the antioxidant enzyme system in colon cancer cells.

Members of the peroxiredoxin (Prx) family, a family of antioxidant enzymes, have been reported to maintain the redox balance in cells by functioning as reactive oxygen species (ROS) scavengers. These members are capable of converting $\mathrm{H}_{2} \mathrm{O}_{2}$ to $\mathrm{H}_{2} \mathrm{O}$ and mediating signal transduction in mammalian cells (4). Among the family members, Prx V is the fifth subfamily of peroxiredoxins, has atypical 2-Cys and is widely distributed in the cytoplasm and mitochondria (5). It has been reported that the expression of $\operatorname{Prx} \mathrm{V}$ is positively correlated with radio-resistance in 
multiple lung carcinoma cell lines (6). A previous study has constructed a U1810 lung carcinoma cell line where Prx V was down-regulated or had impaired enzymatic function and demonstrated the increased sensitivity of these cells to the anticancer drugs etoposide and adriamycin. Pre-treatment of these cells with antioxidant $\mathrm{N}$-acetyl-cysteine (NAC) did not change their sensitivity to adriamycin. Therefore, these results revealed the involvement of $\operatorname{Prx} \mathrm{V}$ in non-redox activities (6). Furthermore, our previous studies have shown that Prx V levels are associated with LPS stimulation in microglia. In an effort to determine the effects of Prx V on oxidative stress-induced cell apoptosis of colon cancer cells, we found that Prx V expression is down-regulated and ROS levels are increased during $\beta$-lapachone-induced SW480 colon cancer cell apoptosis. However, the roles and molecular mechanisms of $\operatorname{Prx} \mathrm{V}$ in $\beta$-lapachone-driven cell apoptosis are not clearly known.

$\beta$-lapachone is a natural naphthoquinone compound extracted from the South American lapacho tree with antioxidative stress and anti-cancer activities (7). $\beta$-lapachone increases $\mathrm{NAD}(+) / \mathrm{NADH}$ ratio in kidney and decreases the renal levels of nuclear $\mathrm{p}-\mathrm{NF}-x \mathrm{~B}$ and its correspondent downstream effectors TNF- $\alpha$, IL- $1 \beta$, IL-6, and iNOS to play a protective role against DOX-induced nephrotoxicity in mice (8). In addition, recent studies have shown that the anticancer effects of $\beta$-lapachone are performed through the inhibition of type II topoisomerase, activation of $\mathrm{NAD}(\mathrm{P}) \mathrm{H}$ : Quinone oxidoreductase I and induction of oxidative stress in numerous cancers (9-13).

In this study, we observed decreased Prx V expression in $\beta$ lapachone-induced SW480 cell apoptosis. Therefore, to further understand the regulatory function of Prx V, the Prx V silenced (shPrx V), mock and Prx V overexpressed (Prx V-His) ASW480 cells were constructed using lentiviral vectors. Cellular apoptosis, ROS levels and apoptosis-related protein expression were also analyzed after treatment of these constructed SW480 cells with $\beta$-lapachone. Furthermore, we verified the signaling pathway associated with $\operatorname{Prx} \mathrm{V}$ in the cell apoptosis process. Altogether, our findings further our understanding of Prx V functions in colon cancer which may be helpful for the successful management of treatments.

\section{Materials and Methods}

Chemicals. Dulbecco's modified Eagle's medium (DMEM) and fetal bovine serum (FBS) were purchased from Hyclone (General Electric Healthcare Life Sciences, Mississauga, Canada), penicillin streptomycin $(\mathrm{P} / \mathrm{S})$ was purchased from solarbio (Solarbio life sciences, Beijing, P.R. China), and $\beta$-lapachone was purchased from Selleck (Selleck Chemicals, Houston, TX, USA).

Cell culture. The human colon cancer cell line (SW480) was obtained from the American Type Culture Collection (ATCC, VA, USA). Cell cultures were maintained in DMEM supplemented with $10 \%(\mathrm{v} / \mathrm{v})$ FBS and penicillin and streptomycin $(100 \mathrm{U} / \mathrm{ml}$ and 100 $\mu \mathrm{g} / \mathrm{ml}$, respectively), and incubated at $37^{\circ} \mathrm{C}$ and $5 \% \mathrm{CO}_{2}$. Cells were sub-cultured every two days.

Generation of stable Prx V knockdown and over-expressed SW480 cells. Short hairpin RNA (shRNA) specific to Prx V (shPrx V LV3, H1\&Puro), his-tag Prx V LV3 (H1\&Puro) and control shRNA LV3 (H1\&Puro) lentivirus vectors were purchased from Shanghai GenePharma Co., Ltd. (Shanghai, China). The corresponding multiplicity of infection was used for transfection according to the lentiviral titer provided by the company. The infection volumes were 200, 200 and 100 for MOCK, shPrx V and Prx V overexpression cells, respectively. The volume of the added virus was calculated by the equation: (unit: $\mathrm{ml}$ )=the number of cells exposed to lentivirus $\times \mathrm{MOI} /$ lentivirus titer (Unit: TU/ml). The targeted sequence of shPrx V was 5'-GGAATCGACGTCTC AAGAGGT-3' and the targeted sequence of the negative control was 5'-GTTCTCCGAACGTGTCACGT-3'. 1×104/well SW480 cells were seeded into96-well culture plates $24 \mathrm{~h}\left(37^{\circ} \mathrm{C}\right.$ and $\left.5 \% \mathrm{CO}_{2}\right)$ prior to transfection. The culture medium was replaced by polybrene ( $5 \mu \mathrm{g} / \mathrm{ml}$; Shanghai GenePharma Co., Ltd.) and packed lentivirus with a 48-h multiplicity of infection, and subsequently replaced with complete culture medium (DMEM with 10\% FBS and antibiotics). Infected cells were selected by treatment with puromycin and genetic in expression levels of Prx V protein were analyzed by western blotting and fluorescent images were taken using a fluorescence microscope three days after selection.

Western blotting analysis. Cell protein lysates were separated on $12 \%$ sodium dodecyl sulfate-polyacrylamide gels and transferred onto nitrocellulose membranes (Millipore, Bedford, MA, USA).The membranes were blotted with primary antibodies against Prx V, histag, Bcl-2, Bad, caspase3, Gsk3- $\beta$, $\beta$-catenin (Santa Cruz, CA, USA), and $\beta$-actin (Sigma, St. Louis, MO, USA) at $4^{\circ} \mathrm{C}$ overnight. The membranes were washed five times with $10 \mathrm{mM}$ Tris- $\mathrm{HCl}$ (pH 7.5) containing $150 \mathrm{mM} \mathrm{NaCl}$ (Tris-buffered saline, TBS) and $0.2 \%$ Tween 20 and subsequently incubated with horseradish peroxidase-conjugated goat anti-rabbit IgG (Sigma) or anti-mouse IgG (Sigma) for $1 \mathrm{~h}$ at room temperature. After the removal of excess antibodies by washing with TBS, specific binding was detected using a chemiluminescence detection system (Amersham, Berkshire, UK) according to the manufacturer's instructions.

Cell viability assay. Cell viability was examined by an MTT assay. SW480 cells were inoculated in a density of 10,000 cells per well in 96-well plates and treated with $0-2.5 \mu \mathrm{M}$ of $\beta$-lapachone for $24 \mathrm{~h}\left(37^{\circ} \mathrm{C}\right.$ and $5 \% \mathrm{CO}_{2}$ ), while control cells were incubated with media without $\beta$-lapachone. The accumulation of formazan (dissolved with dimethylsulfoxide) was determined following the addition of MTT reagent $(5 \mathrm{mg} / \mathrm{ml})$ and the absorbance was measured at a wavelength of $490 \mathrm{~nm}$. Absorbance was detected by a UV max Kinetic microplate reader (Molecular Devices, LLC, Sunnyvale, CA, USA).

Cell apoptosis and ROS detection. To confirm the rate of cell apoptosis and ROS levels, $\beta$-lapachone-treated SW480 cells were recovered using trypsin, re-suspended with PBS and stained with AnnexinV-Phycoerythrin (PE) (for apoptosis) and DHE (for ROS), with the apoptosis/ROS detection kit according to the manufacturer's protocol (BD Biosciences, Franklin Lakes, NJ, USA). The Annexin-PE and DHE positive cells were tested by fluorescence microscopy and flow cytometry on a BD FACS 
A

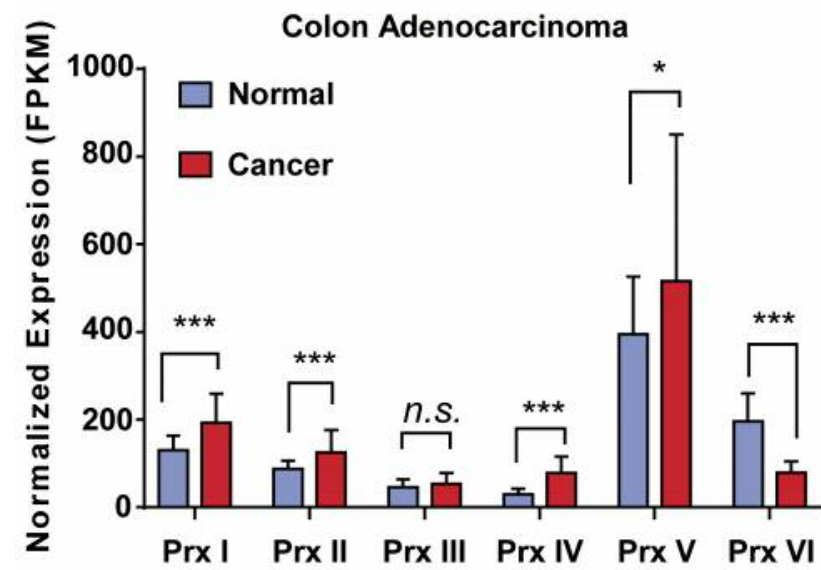

C

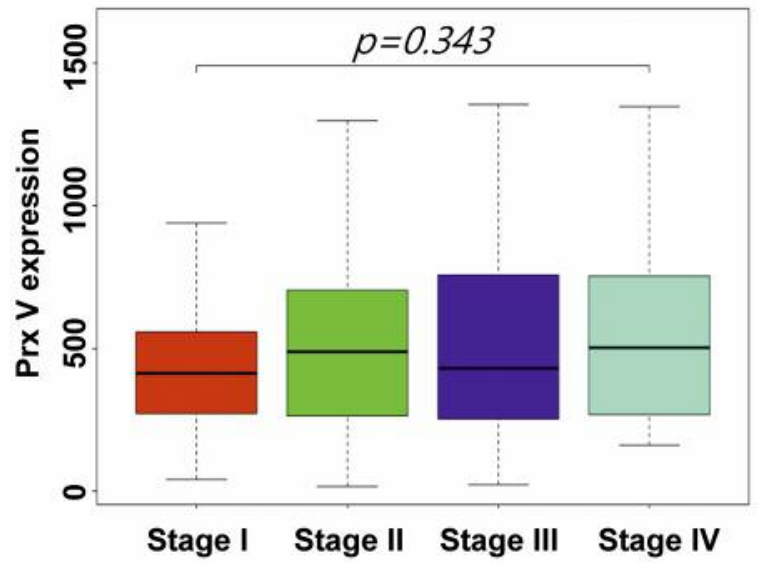

Calibur (BD Biosciences). The results were analyzed with WinMIDI (version 2.9; BD Biosciences) software.

Statistical analysis. The data are depicted as the means \pm SEM. Student's $t$-tests were performed using GraphPad Prism 4.0 software (GraphPad Software Inc., San Diego, CA, USA), and $p<0.05$ was considered to indicate a significant difference.

\section{Results}

Expression of Prx $V$ is increased in colon cancer tissues compared to normal colorectal tissues. Elevated expression levels of Prx V have been reported in colon cancer tissues compared with normal tissues (14). Therefore, to compare the expression of Prx V in colon cancer tissues with normal colon tissues, we used the GEPIA website from the ATGC database. As shown in Figure 1A, we first analyzed the
B

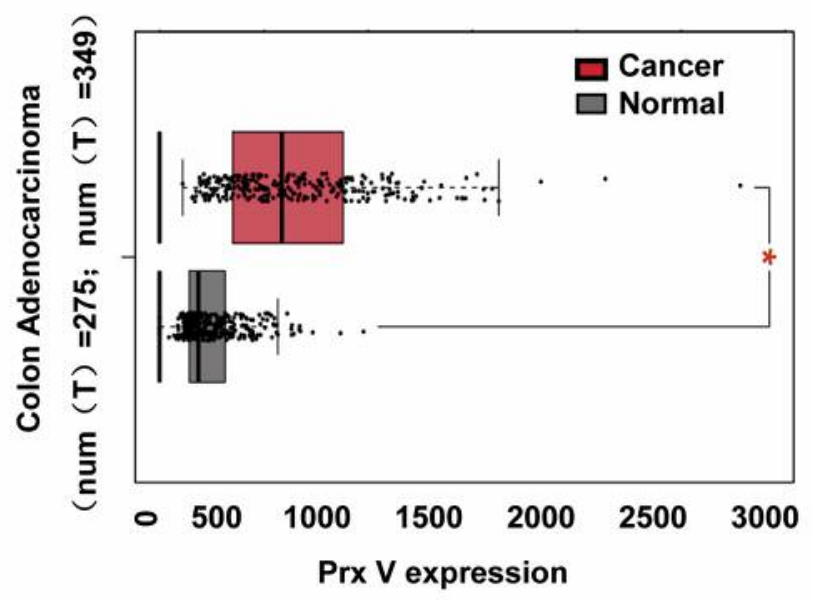

Figure 1. Expression of Prx V in normal and cancerous colon tissues. (A) The expression of peroxiredoxin family members in normal and cancerous colon tissues. (B) The expression of Prx $V$ in normal and cancerous colon tissues. (C) The expression of Prx $V$ in four stages of colon cancer as obtained by GEPIA website from ATGC database.

expression of Prx family members in normal and cancerous colon tissues. Among all the family members, Prx V expression was significantly higher compared to other Prx family members in both tissue types. When comparing normal and cancerous colon tissues, Prx V expression was higher in cancerous tissues than normal tissues as shown in Figure $1 \mathrm{~A}$ and B. Also, no significant change in the expression of Prx V between the four stages of colon cancer was observed (Figure 1C).

Confirmation of Prx $V$ expression in constructed mock, shPrx $V$ and Prx V-His SW480 CRC cells. The purpose of this study was to check the potential role of $\operatorname{Prx} \mathrm{V}$ in colon cancer cell apoptosis. Therefore, we constructed Prx V silenced (shPrx V), overexpressed (Prx V-His) and mock SW480 cells using lentiviral vectors for our further studies 

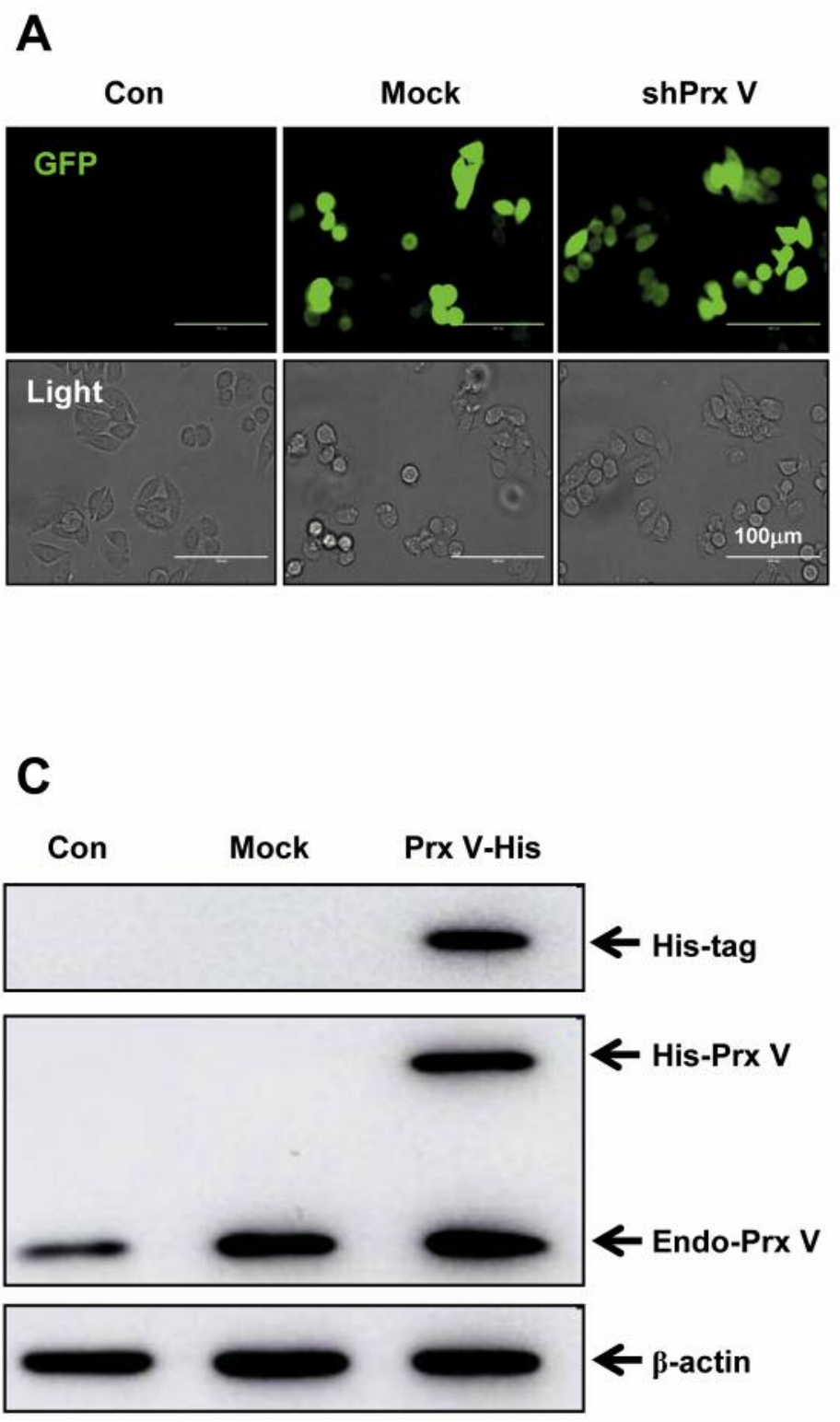

B

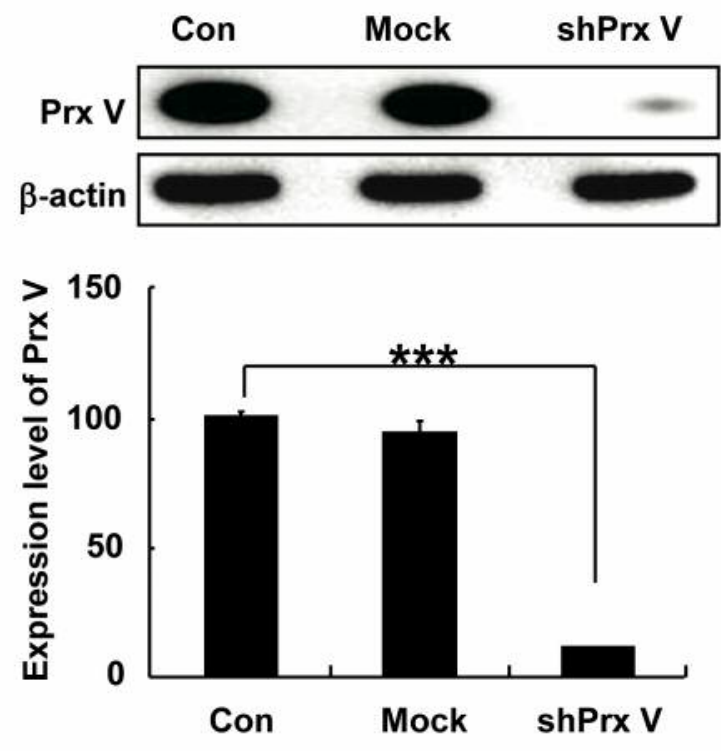

Figure 2. Successful generation of Mock, shPrx V and Prx V-His SW480 cell lines. (A) Fluorescence imaging of the constructed cell lines to detect GFP. (B) Western blotting to assess the expression of Prx V in 3 constructed cell lines and confirm the successful generation of cell lines. (C) Western blotting to examine the expression of Prx V-His in Prx V-His cell line. The protein expression is presented as the means \pm standard deviation, $* p<0.05, * * p<0.01, * * * p<0.01$. Three independent replicates were performed for all the experiments.

on apoptosis. As shown in Figure 2A, we confirmed the construction of the different SW480 colon cancer cell lines by fluorescence microscopy and then by western blot analysis. As shown in Figure 2B, expression of Prx $\mathrm{V}$ was significantly reduced in shPrx $\mathrm{V}$ cells compared with control and mock cells. Similarly, construction of $\operatorname{Prx} V$ overexpressed cells was further confirmed by the higher expression of His-Prx V as shown in Figure 2C.

Prx V suppresses $\beta$-lapachone-induced apoptosis of SW480 $C R C$ cells. To induce apoptosis, $\beta$-lapachone was used, as it has already been reported that $\beta$-lapachone induces apoptosis and cell cycle arrest of colon cancer cells (15). It has also been demonstrated that $\beta$-lapachone is capable of inhibiting lung metastasis of colon cancer cells (16). Similarly, our results also showed that mock, shPrx V and His-Prx V SW480 colon cancer cell viability was reduced with increasing concentrations of $\beta$-lapachone $(0 \mu \mathrm{M}, 1$ $\mu \mathrm{M}, 1.5 \mu \mathrm{M}, 2 \mu \mathrm{M}$, and $2.5 \mu \mathrm{M}$ ) for $24 \mathrm{~h}$ as shown in Figure $3 \mathrm{~A}$ by the MTT assay. Interestingly, the results showed that compared to Mock cells, shPrx V cells had a prominent reduction in cell viability. However, the viability of His-Prx V cells was higher than that in Mock SW480 cells as shown in Figure $3 \mathrm{~A}$. To further study the role of 
A
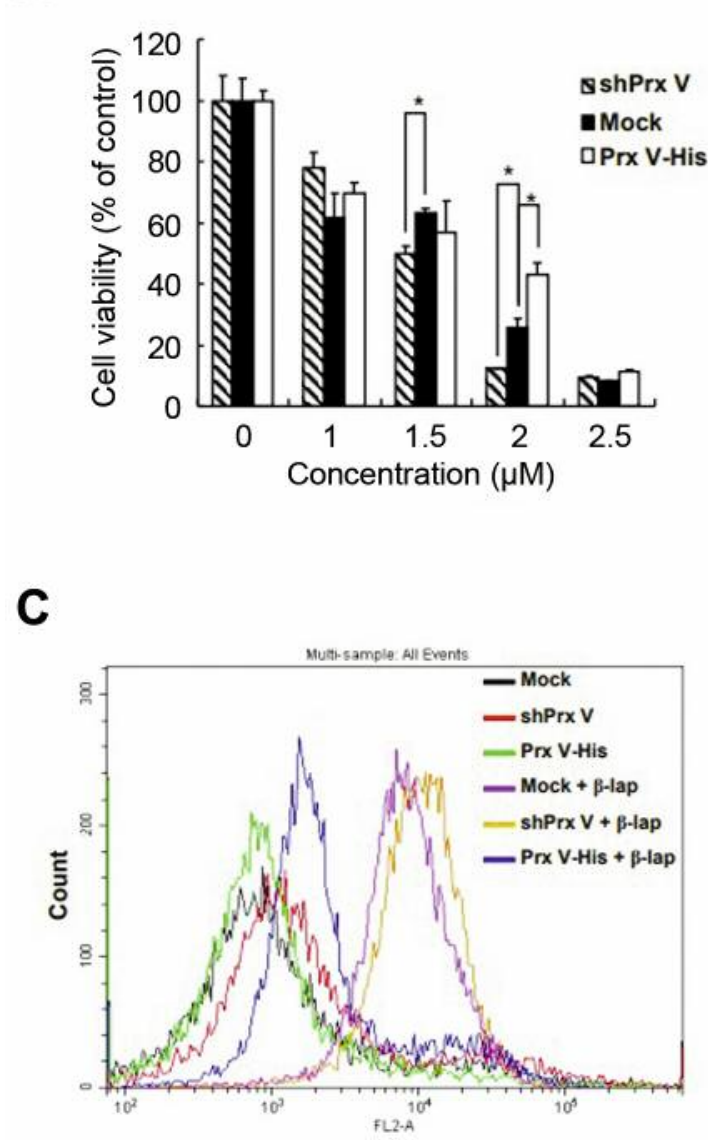
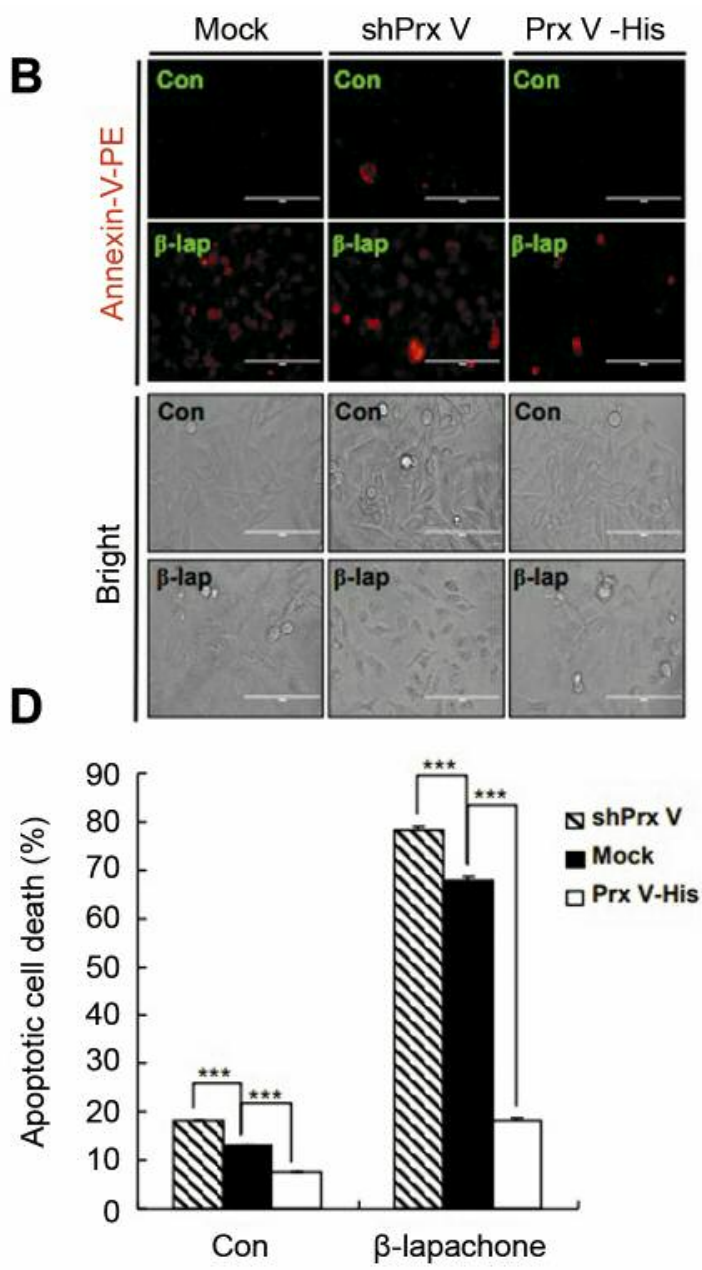

Figure 3. Prx V is associated with apoptosis of colon cancer cells. (A) Cell viability of Mock, shPrx V and Prx V-His SW480 cells after treatment with $\beta$-lapachone in a dose-dependent manner $(0,1,1.5,2$ and $2.5 \mu M)(B)$ Annexin $V$-PE staining $(C)$ flow cytometry and $(D)$ quantitative data of flow cytometry to observe the effects of treatment for $24 \mathrm{~h}$ with $2 \mu \mathrm{M} \beta$-lapachone.

Prx V in colon cancer cell apoptosis, we conducted Annexin V staining assay after treating Mock, shPrx V and His-Prx V cells with $2 \mu$ Mof $\beta$-lapachone for $24 \mathrm{~h}$. As shown in Figure3B, apoptosis was higher in shPrx V cells and lower in Prx V-His cells compared to Mock SW480 cells. These Prx V effects on colon cancer cell apoptosis were confirmed by flow cytometry as shown in Figure 3C. Quantification of the percentage apoptotic cell death is presented in Figure 3D. These results suggested that Prx V is capable of inhibiting apoptosis caused by $\beta$-lapachone in SW480 colon cancer cells.

Overexpression of Prx V significantly affects apoptosis-related protein expression in colon cancers. To further study the role of Prx V in colon cancer cell apoptosis, western blotting was used to examine the expression of apoptosis-related proteins such as $\mathrm{Bcl} 2, \mathrm{Bcl}-\mathrm{xL}$ and Bad in $\beta$-lapachone-treated Mock, shPrx V and His-Prx V SW480 cells. Bcl2 and Bcl-xL are considered as anti-apoptotic proteins which inhibit apoptosis (17) and $\mathrm{Bad}$ is considered as a pro-apoptotic protein which promotes cell apoptosis (18). As shown in Figure 4A, B and C, the expression of $\mathrm{Bcl} 2$ was reduced upon treatment with $\beta$-lapachone, however the reduction was more significant in Mock and shPrx $\mathrm{V}$ cell lines compared to Prx V-His cells. As a shown in Figure 4A, B and $\mathrm{C}$, treatment of Mock and shPrx V transfected cells with $\beta$ lapachone resulted in higher decrease in the expression of Bcl$\mathrm{xL}$ protein compared to $\beta$-lapachone-treated Prx V-His SW480 cells. Moreover, the expression of pro-apoptotic Bad protein was increased at higher levels in Mock and shPrx V SW480 cells with $\beta$-lapachone compared to Prx V-His cells. These results suggest that $\operatorname{Prx} \mathrm{V}$ modulates the expression of apoptosis-related proteins in colon cancer cells and confirm that Prx V plays a pivotal role in colon cancer cell apoptosis induced by $\beta$-lapachone. 
A

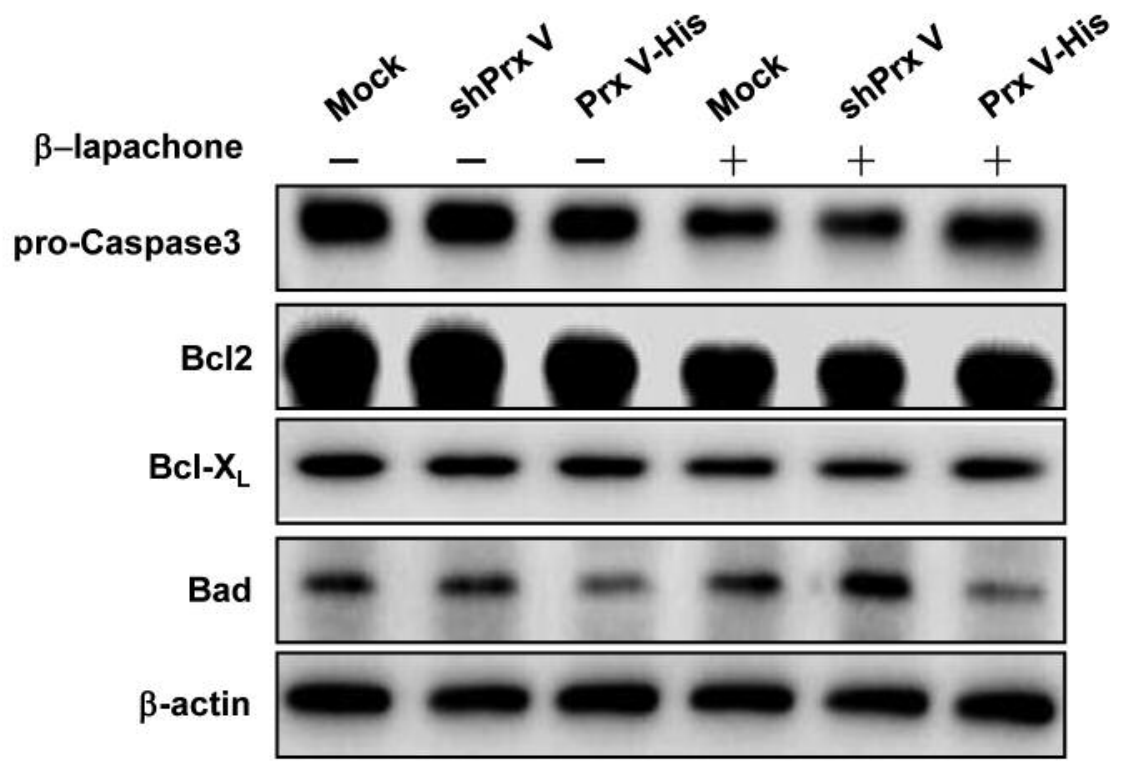

B
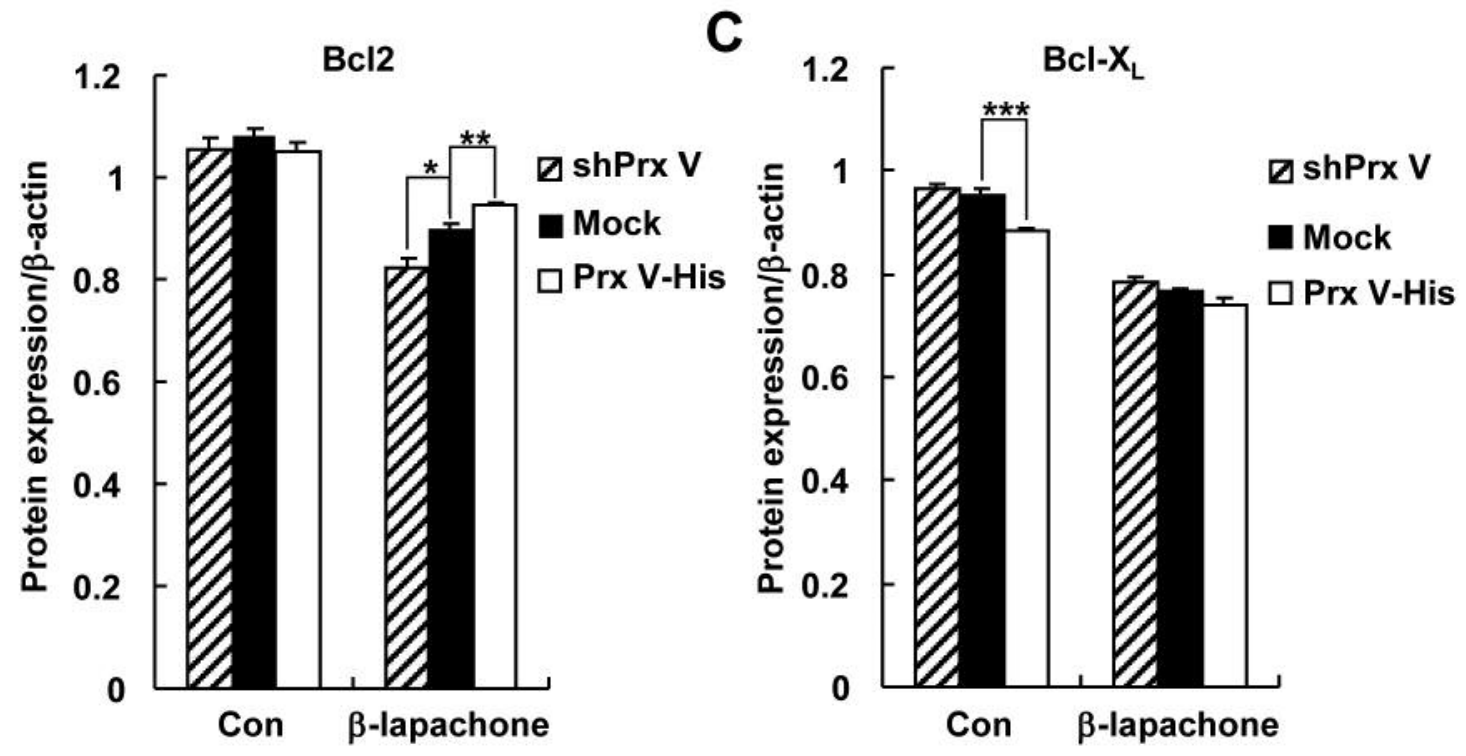

Figure 4. Prx V modulates the expression of apoptosis-related protein in colon cancers. (A) Western blotting of extracts of Mock, shPrx V and Prx $V$-His transfected cells, to investigate the effect of $2 \mu \mathrm{M}$ of $\beta$-lapachone on the expression of apoptosis-related proteins pro-caspase 3, Bcl2, Bcl-xL and Bad. $(B, C)$ The quantitative expression of western blotting data.

$\beta$-lapachone induced ROS levelsinSW480 cells are influenced by Prx $V$ expression levels. Increased levels of ROS are related with colon cancer cell apoptosis (19). Therefore, we investigated the effect of $\operatorname{Prx} \mathrm{V}$ on $\beta$-lapachone induced ROS levelsinSW480 cells. As shown in Figure 5A, B and C, fluorescence microscopic images of DHE and DAPI staining, flow cytometry and quantitative data showed that ROS levels are increased significantly upon treatment of Mock and shPrx V SW480 cells with $\beta$-lapachone. However, ROS levels were not significantly increased in $\beta$-lapachone-treated Prx V-His cells. These results demonstrate that overexpression of $\operatorname{Prx} \mathrm{V}$ regulates tSW480 cell apoptosis via scavenging cellular ROS levels.

Overexpression of Prx $V$ significantly reduces $\beta$-lapachone induced apoptosis by inhibiting the Wnt/ $\beta$-catenin signaling 

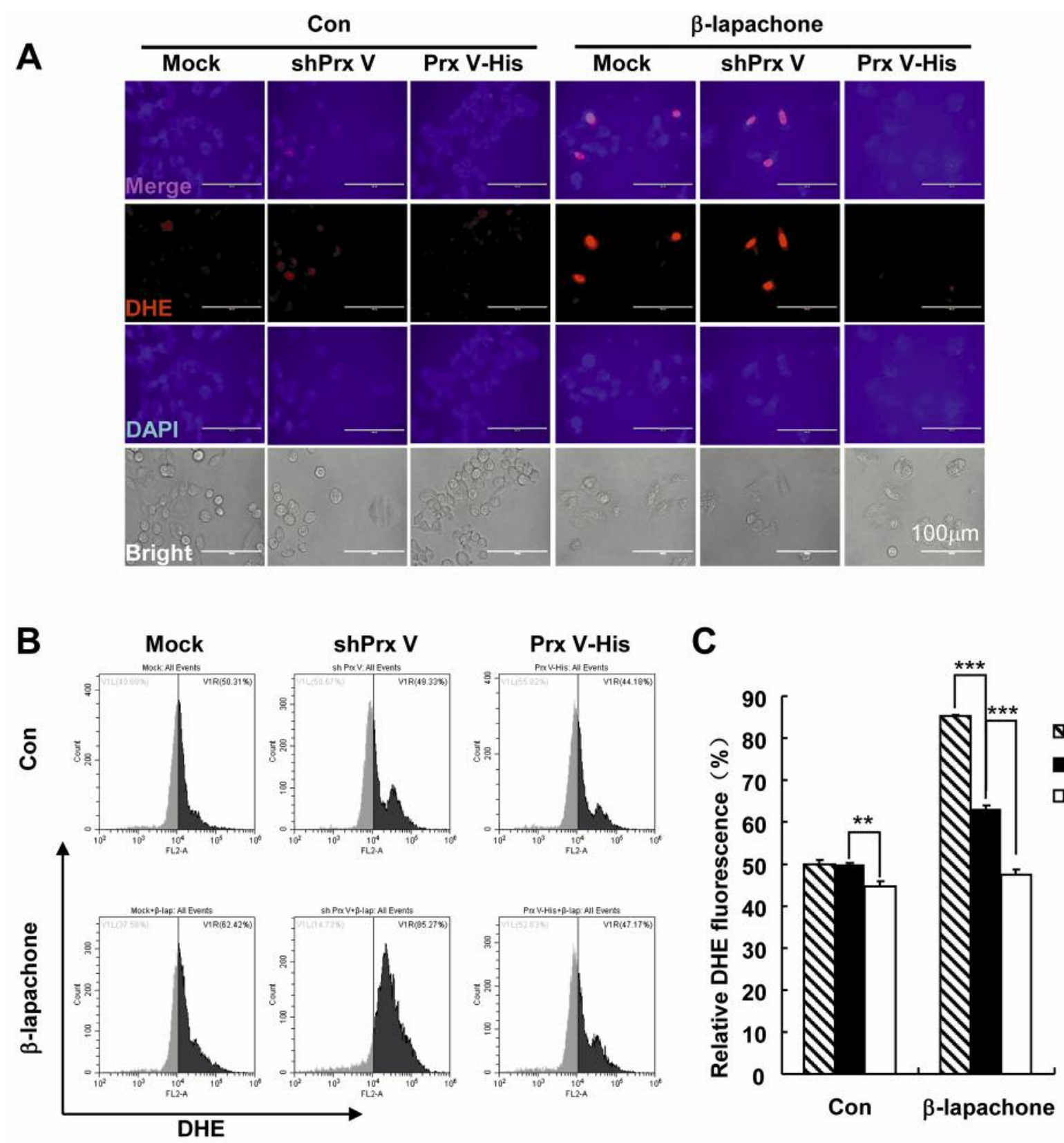

Figure 5. Over-expression of Prx V reduces $\beta$-lapachone-induced SW480 cell apoptosis. (A) DHE and DAPI staining of Mock, shPrx V and Prx VHis SW480 colon cancer cells after treatment with $2 \mu \mathrm{M}$ of $\beta$-lapachone for $24 \mathrm{~h}$. (B) Flow cytometric analysis and (C) its quantification of the results.

pathway. To explore the underlying mechanism of the effect of Prx V in $\beta$-lapachone-induced apoptosis in SW480 colon cancer cells, the expression levels of Gsk3- $\beta$ and $\beta$-catenin, two proteins involved in the $\mathrm{Wnt} / \beta$-catenin signaling pathway, were analyzed. As shown in Figure 6A, B and C, western blot analysis showed that the expression of p-Gsk3- $\beta$ /Gsk3- $\beta$ was higher in Prx V-His cells than Mock and shPrx V SW480 cells. In contrast, the expression of $\mathrm{p}$ - $\beta$-catenin/ $\beta$-catenin was reduced in Prx V overexpressed cells compared with Mock and shPrx V SW480 cells. Altogether, these data suggest that overexpression of Prx V may modulate $\beta$-lapachone-induced apoptosis of SW480 colon cancer cells through the $\mathrm{Wnt} / \beta$-catenin signaling pathway. 

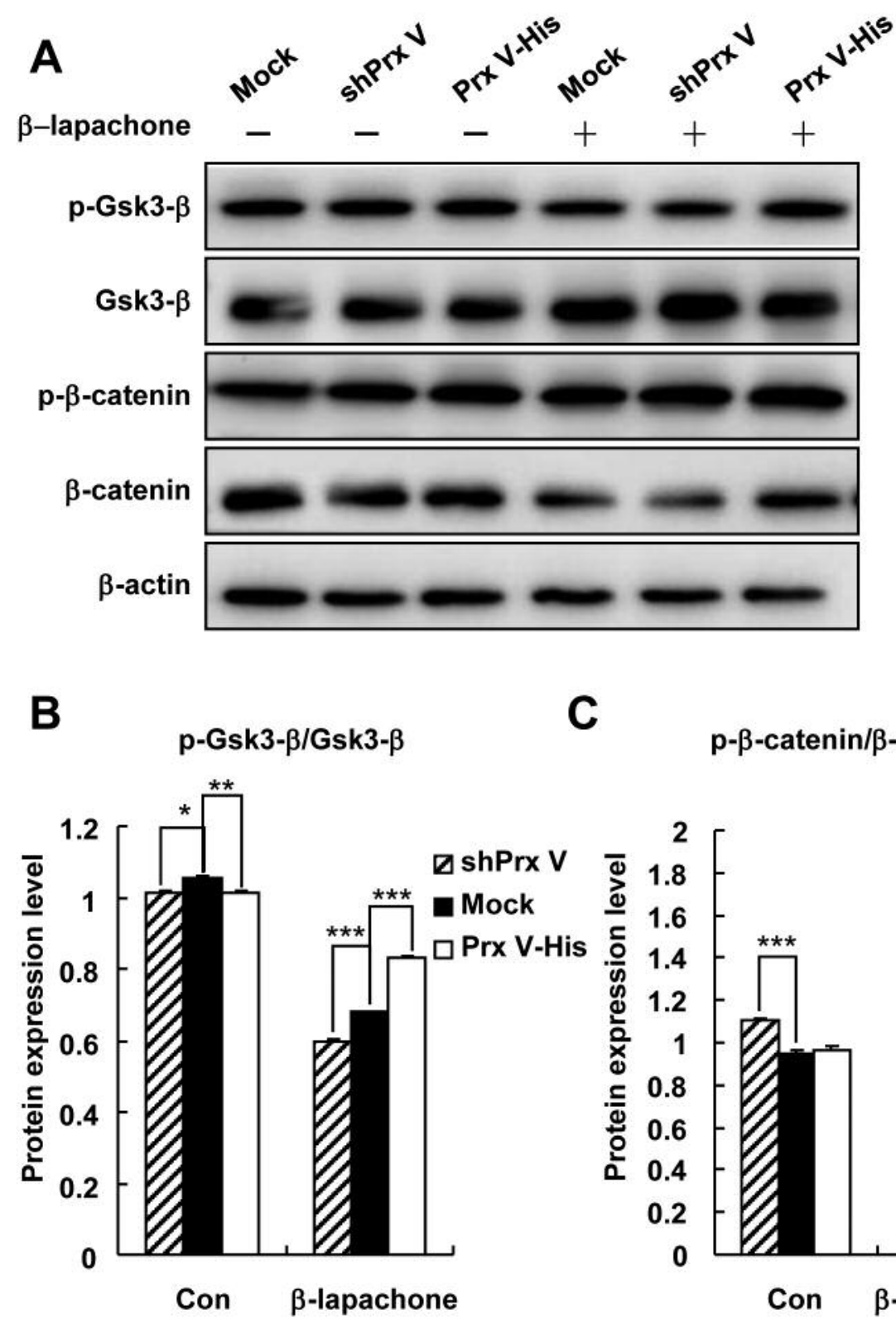

C $\quad$ - $\beta$-catenin/ $\beta$-catenin

Figure 6. Overexpression of Prx V affects $\beta$-lapachone-induced apoptosis through Wnt/ $\beta$-catenin signaling pathway. (A) Western blotting to examine the changes in the expression of Wnt/ $\beta$-catenin signaling pathway-related proteins in Mock, shPrx V and Prx V-His SW480 cell lines after treatment with $2 \mu M$ of $\beta$-lapachone for $24 h .(B, C)$ Quantitation of the western blotting results.

\section{Discussion}

Colon cancer is responsible for almost 700,000 deaths every year worldwide. The incidence of colon cancer is higher in developed countries and is increasing continuously (1). Colon cancer requires around 2-5 years to develop, allowing time for early diagnosis if the proper diagnostic facilities are available (20). Currently, there are

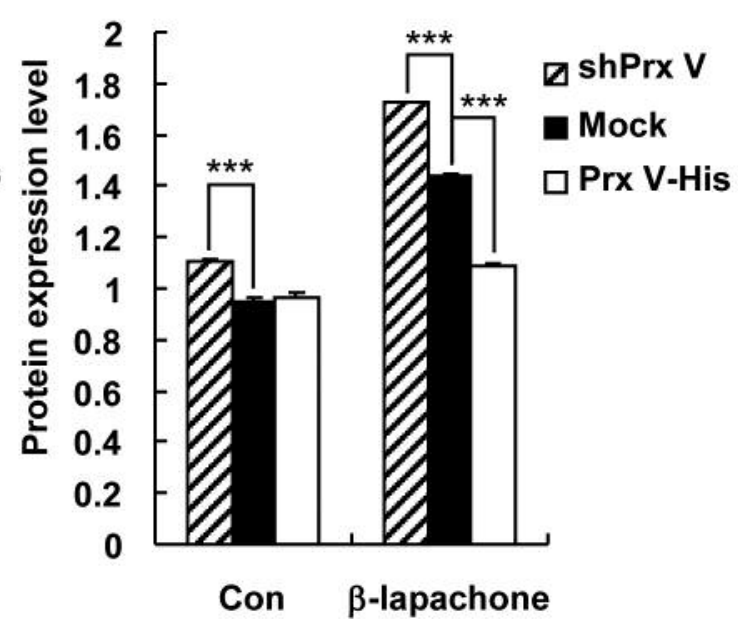

GhPrx V

Mock

Prx V-His 
In this study, we focused on the peroxiredoxin family, a large and conserved antioxidant enzyme family (22), in colon cancer cells and its role in colon cancer cell apoptosis. Involvement of Prx family members in the different stages of numerous cancers, including colon cancer, has already been reported in previous studies (23-25). Therefore, first we checked the expression of Prx family members in colon cancer tissues compared with normal colon tissues using GEPIA website from the ATGC database. According to our data, all Prx family members except Prx VI were highly expressed in colon cancer tissues compared to normal colon tissues. Among them, the expression of Prx V was increased in both colon cancer and normal colon tissues compared with other Prx family members.

Therefore, we have focused on the expression of Prx $\mathrm{V}$ in colon cancer tissues. Our results further confirmed that the expression of Prx V is higher in colon cancer tissues than normal colon tissues and also showed that there is no change in Prx V expression between the four stages of colon cancer. Also, Prx V has already been reported to promote the epithelial-mesenchymal transition (EMT) in colon cancer (14), but, its effects on colon cancer cell apoptosis have not been reported. Thus, to further understand the role of Prx V in colon cancer cell apoptosis, we constructed 3 stable SW480 cell lines including control (Mock), Prx V downregulated (shPrx V) and Prx V overexpressed (Prx V-His). These cell lines were then utilized for studying the relationship between the expression of Prx V and colon cancer cell apoptosis. $\beta$-lapachone was used to induce cell apoptosis of colon cancer cells. $\beta$-lapachone has already been identified for its ability to induce cell-cycle arrest and cell apoptosis in colon cancer (15).

Induction of colon cancer cell apoptosis by $\beta$-lapachone was confirmed by a dose-dependent $(0,11.5,2$ and $2.5 \mu \mathrm{M})$ treatment of cells and analysis of cell viability by MTT assay. Based on these data, we selected $2 \mu \mathrm{M}$ of $\beta$-lapachone treatment for $24 \mathrm{~h}$ as the standard for further experiments. In our current study, we observed that overexpression of Prx V inhibited the $\beta$ lapachone-induced colon cancer cell apoptosis by Annexin V staining and flow cytometry. Moreover, Prx V also modulated the expression of apoptosis-related markers in colon cancer cells. Altogether, these data indicated that the overexpression of Prx V suppresses cell apoptosis in colon cancers. Not only cell apoptosis but also the levels of ROS in colon cancer cells induced by $\beta$-lapachone were affected by the overexpression of Prx V as observed by DHE, DAPI staining and flow cytometry. Taken together, these results demonstrated that Prx V protects colon cancer cells by inhibiting ROS-mediated cell apoptosis (26). It has been reported that the $\beta$-catenin signaling pathway is involved in the apoptosis of colon cancer cells $(27,28)$. Therefore, to investigate whether Prx V-mediated inhibition of colon cancer cell apoptosis is related with the $\mathrm{Wnt} / \beta$-catenin signaling pathway, we conducted western blotting to analyze the expression of proteins involved in the pathway. p-Gsk3- $\beta$ / Gsk3- $\beta$ was higher in Prx V-His cells than Mock and shPrx V SW480 cells. Furthermore, $\mathrm{p}$ - $\beta$-catenin $/ \beta$-catenin levels were reduced in Prx V-His cells compared with Mock and shPrx V SW480 cells. Altogether, these results confirmed that the Prx V-mediated inhibition of colon cancer cell apoptosis is associated with Wnt/ $\beta$-catenin signaling pathway.

In conclusion, we showed that overexpression of Prx V inhibits cell apoptosis via regulating ROS levels and Wnt/ $\beta$-catenin signaling pathway in colon cancers. Expression of apoptosis-related markers was also affected by the levels of Prx $\mathrm{V}$. Taken together, these results provide a new insight into the underlying mechanisms of colon cancer cell apoptosis related to the expression of Prx V. However, further studies should be conducted to understand these mechanisms in depth.

\section{Funding}

This study was supported by grants from the KRIBB Research Initiative Program (KGM5161914). This research was supported by Basic Science Research Program through the National Research Foundation of Korea (NRF) funded by the Ministry of Education (2017R1D1A1B03028188). KRIBB-OGM5201922.

\section{Conflicts of Interest}

The Authors declare that there are no conflicts of interest regarding this study.

\section{Authors' Contributions}

Y.L., T.K., N.C. performed the construct the model and writing the manuscript. T.K., Y.H.J., Y.X.G., D.P.X. and Y.H.H. performed the analysis of apoptosis/ROS levels and the image analysis. T.K., M.H.J., G.N.S., J.S.K., and D.K.J. performed the data analysis, T.K., D.S.L., Y.D.C. and H.N.S. were substantial contributions to conception and design. All Authors read and approved the final manuscript.

\section{Acknowledgements}

This research was supported by the project for postgraduate to innovate scientific research in Heilongjiang Bayi Agricultural University (No: YJSCX2018-Y60), NRF-2016R1A6A1A03012862.

\section{References}

1 Brody H: Colorectal cancer. Nature 521(7551): S1, 2015. PMID: 25970450. DOI: $10.1038 / 521 \mathrm{~S} 1 \mathrm{a}$

2 Zeng M, Zhu L, Li L and Kang C: Mir-378 suppresses the proliferation, migration and invasion of colon cancer cells by inhibiting sdad1. Cell Mol Biol Lett 22: 12, 2017. PMID: 28725241. DOI: 10.1186/s11658-017-0041-5

3 Hing TC, Ho S, Shih DQ, Ichikawa R, Cheng M, Chen J, Chen X, Law I, Najarian R, Kelly CP, Gallo RL, Targan SR, Pothoulakis $\mathrm{C}$ and Koon HW: The antimicrobial peptide cathelicidin modulates clostridium difficile-associated colitis and toxin a-mediated enteritis in mice. Gut 62(9): 1295-1305, 2013. PMID: 22760006. DOI: 10.1136/gutjnl-2012-302180 
4 Wood ZA, Schroder E, Robin Harris J and Poole LB: Structure, mechanism and regulation of peroxiredoxins. Trends Biochem Sci 28(1): 32-40, 2003. PMID: 12517450. DOI: 10.1016/S09680004(02)00003-8

5 Hall A, Nelson K, Poole LB and Karplus PA: Structure-based insights into the catalytic power and conformational dexterity of peroxiredoxins. Antioxid Redox Signal 15(3): 795-815, 2011. PMID: 20969484. DOI: 10.1089/ars.2010.3624

6 Kropotov A, Gogvadze V, Shupliakov O, Tomilin N, Serikov $\mathrm{VB}$, Tomilin NV and Zhivotovsky B: Peroxiredoxin $\mathrm{v}$ is essential for protection against apoptosis in human lung carcinoma cells. Exp Cell Res 312(15): 2806-2815, 2006. PMID: 16781710. DOI: 10.1016/j.yexcr.2006.05.006

7 Schaffner-Sabba K, Schmidt-Ruppin KH, Wehrli W, Schuerch AR and Wasley JW: Beta-lapachone: Synthesis of derivatives and activities in tumor models. J Med Chem 27(8): 990-994, 1984. PMID: 6205152. DOI: 10.1021/jm00374a010

8 Sanajou D, Nazari Soltan Ahmad S, Hosseini V, KalantaryCharvadeh A, Marandi Y, Roshangar L, Bahrambeigi S and Mesgari-Abbasi M: Beta-lapachone protects against doxorubicininduced nephrotoxicity via nad(+)/ampk/nf-kb in mice. Naunyn Schmiedebergs Arch Pharmacol 392(5): 633-640, 2019. PMID: 30671613. DOI: 10.1007/s00210-019-01619-0

9 Silvers MA, Deja S, Singh N, Egnatchik RA, Sudderth J, Luo X, Beg MS, Burgess SC, DeBerardinis RJ, Boothman DA and Merritt ME: The nqo1 bioactivatable drug, beta-lapachone, alters the redox state of nqo1+ pancreatic cancer cells, causing perturbation in central carbon metabolism. J Biol Chem 292(44): 18203-18216, 2017. PMID: 28916726. DOI: 10.1074/jbc.M117. 813923

10 Motea EA, Huang X, Singh N, Kilgore JA, Williams NS, Xie XJ, Gerber DE, Beg MS, Bey EA and Boothman DA: Nqo1dependent, tumor-selective radiosensitization of non-small cell lung cancers. Clin Cancer Res 25(8): 2601-2609, 2019. PMID: 30617135. DOI: 10.1158/1078-0432.CCR-18-2560

11 Kim DW and Cho JY: Nqo1 is required for beta-lapachone-mediated downregulation of breast-cancer stem-cell activity. Int J Mol Sci 19(12), 2018. PMID: 30513573. DOI: 10.3390/ ijms19123813

12 Lamberti MJ, Morales Vasconsuelo AB, Chiaramello M, Ferreira VF, Macedo Oliveira M, Baptista Ferreira S, Rivarola VA and Rumie Vittar NB: Nqo1 induction mediated by photodynamic therapy synergizes with beta-lapachone-halogenated derivative against melanoma. Biomed Pharmacother 108: 1553-1564, 2018. PMID: 30372857. DOI: 10.1016/j.biopha.2018.09.159

$13 \mathrm{Li} \mathrm{N}$, Wang C, Zhang P and You S: Emodin inhibits pancreatic cancer emt and invasion by upregulating microrna1271. Mol Med Rep 18(3): 3366-3374, 2018. PMID: 30066876. DOI: 10.3892/mmr.2018.9304

14 Ahn HM, Yoo JW, Lee S, Lee HJ, Lee HS and Lee DS: Peroxiredoxin 5 promotes the epithelial-mesenchymal transition in colon cancer. Biochem Biophys Res Commun 487(3): 580586, 2017. PMID: 28431931. DOI: 10.1016/j.bbrc.2017.04.094

15 Huang L and Pardee AB: Beta-lapachone induces cell cycle arrest and apoptosis in human colon cancer cells. Mol Med 5(11): 711-720, 1999. PMID: 10656873. DOI: 10.1007/BF03 402095

16 Kee JY, Han YH, Park J, Kim DS, Mun JG, Ahn KS, Kim HJ, Um JY and Hong SH: Beta-lapachone inhibits lung metastasis of colorectal cancer by inducing apoptosis of ct26 cells. Integr Cancer Ther 16(4): 585-596, 2017. PMID: 27923905. DOI: $10.1177 / 1534735416681638$
17 Hata AN, Engelman JA and Faber AC: The bcl2 family: Key mediators of the apoptotic response to targeted anticancer therapeutics. Cancer Discov 5(5): 475-487, 2015. PMID: 25895919. DOI: $10.1158 / 2159-8290$.CD-15-0011

18 Bogdal MN, Hat B, Kochanczyk M and Lipniacki T: Levels of pro-apoptotic regulator bad and anti-apoptotic regulator bcl-xl determine the type of the apoptotic logic gate. BMC Syst Biol 7(67), 2013. PMID: 23883471. DOI: 10.1186/1752-0509-7-67

19 Zhuge W, Chen R, Vladimir K, Dong X, Zia K, Sun X, Dai X, Bao M, Shen X and Liang G: Costunolide specifically binds and inhibits thioredoxin reductase 1 to induce apoptosis in colon cancer. Cancer Lett 412: 46-58, 2018. PMID: 29037867. DOI: 10.1016/j.canlet.2017.10.006

20 Liu G and Li B: Role of mirna in transformation from normal tissue to colorectal adenoma and cancer. J Cancer Res Ther 15(2): 278285, 2019. PMID: 30964098. DOI: 10.4103/ jcrt.JCRT_135_18

21 Roncucci L and Mariani F: Prevention of colorectal cancer: How many tools do we have in our basket? Eur J Intern Med 26(10): 752-756, 2015. PMID: 26499755. DOI: 10.1016/j.ejim.2015. 08.019

22 Cao Z and Lindsay JG: The peroxiredoxin family: An unfolding story. Subcell Biochem 83: 127-147, 2017. PMID: 28271475. DOI: 10.1007/978-3-319-46503-6_5

$23 \mathrm{Li}$ HX, Sun XY, Yang SM, Wang Q and Wang ZY: Peroxiredoxin 1 promoted tumor metastasis and angiogenesis in colorectal cancer. Pathol Res Pract 214(5): 655-660, 2018. PMID: 29673884. DOI: 10.1016/j.prp.2018.03.026

24 Cha MK, Suh KH and Kim IH: Overexpression of peroxiredoxin i and thioredoxin1 in human breast carcinoma. J Exp Clin Cancer Res 28: 93, 2009. PMID: 19566940. DOI: 10.1186/1756-9966-28-93

25 Peng L, Wang R, Shang J, Xiong Y and Fu Z: Peroxiredoxin 2 is associated with colorectal cancer progression and poor survival of patients. Oncotarget 8(9): 15057-15070, 2017. PMID: 28125800. DOI: 10.18632 /oncotarget.14801

26 Agarwal A, Kasinathan A, Ganesan R, Balasubramanian A, Bhaskaran J, Suresh S, Srinivasan R, Aravind KB and Sivalingam N: Curcumin induces apoptosis and cell cycle arrest via the activation of reactive oxygen species-independent mitochondrial apoptotic pathway in smad4 and p53 mutated colon adenocarcinoma ht29 cells. Nutr Res 51: 67-81, 2018. PMID: 29673545. DOI: 10.1016/j.nutres.2017.12.011

27 Jia Y, Chen L, Guo S and Li Y: Baicalin induced colon cancer cells apoptosis through mir-217/dkk1-mediated inhibition of wnt signaling pathway. Mol Biol Rep 46(2): 1693-1700, 2019. PMID: 30737617. DOI: 10.1007/s11033-019-04618-9

28 Piao SS and Shang B: Pizotifen inhibits the proliferation and migration of colon cancer het116 cells by down-regulating wnt signaling pathway. Ann Clin Lab Sci 49(2): 183-188, 2019. PMID: 31028062. 